\title{
Fatigue crack growth in welded S355 specimens subjected to combined loading
}

\author{
J. Lewandowski, D. Rozumek, Z. Marciniak \\ Opole University of Technology, Poland \\ janusz210@mp.pl \\ d.rozumek@po.opole.pl, bttp://orcid.org/0000-0003-2866-2041 \\ z:marciniak@po.opole.pl, http:/ /orcid.org/0000-0001-7071-4488 \\ G. Lesiuk \\ Wrockaw University of Science and Technology, Poland \\ grzegorz:lesink@pwr.edu.pl bttp:/ / orcid.org/0000-0003-3553-6107 \\ R. Brighenti \\ University of Parma, Italy \\ roberto.brighenti@unipr.it, bttp://orcid.org/0000-0002-9273-0822
}

\begin{abstract}
The paper presents the results of experimental fatigue tests performed on welded S355 specimens subjected to combined bending and torsion loading. In order to analyse how the fillet joints' shape and the load ratio affect the crack growth, we selected two kinds of fillet shape: concave and convex, and two load ratios, namely $\mathrm{R}=-1,0$. Rectangular specimens with stress concentrators in the form of the external two-sided blunt notches and fillet welded joint were tested. The test results were compared to experiments conducted on solid specimens without welds.
\end{abstract}

KEYwORDs. Welding; Combined loading; Fatigue crack; Microhardness.

\section{OPEN ACCESS}

Citation: Lewandowski, J., Rozumek, D., Marciniak, Z., Lesiuk, G., Brighenti, R. Fatigue crack growth in welded S355 specimens subjected to combined loadings, Frattura ed Integrità Strutturale, 48 (2019) ww-zz.

Received: 15.11 .2018

Accepted: 20.12 .2018

Published: 01.04.2018

Copyright: (C) 2019 This is an open access article under the terms of the CC-BY 4.0, which permits unrestricted use, distribution, and reproduction in any medium, provided the original author and source are credited.

\section{INTRODUCTION}

any kinds of research are devoted at describing the behaviour of crack growth in structural component [1-6] and joints [7-10]. Fatigue crack growth in welded joints is still a very attractive engineering problem, because of the occurrence of various types of crack initiators, such as geometrical and microstructural notches or residual 
stresses, as well as the presence of numerous non-metallic inclusions and weld defects. Beside the above-mentioned problems, the weld process leads to a very heterogeneous material microstructure because of the thermal effects, which can also induce the distortion of the structural component.

In [11] the influence of various weld imperfection on fatigue crack propagation has been considered. Specimens were subjected to combined axial and torsional loading. Tests revealed the significant detrimental influence of imperfections on the fracture propagation. The problem of evaluation of the fatigue strength of transverse fillet joints was considered in [12]; the authors analyzed three evaluation methods, namely, the hot spot stress method (HSS), the $1 \mathrm{~mm}$ stress method and the linear elastic fracture mechanics (LEFM) approach and compared the results with data from the literature. The comparison showed that the HSS method is too conservative, while the best evaluation was obtained through the use of the Newman and Raju stress intensity factor (SIF) equations within the LEFM method. The development of fatigue cracks in welded joints can also be influenced by the load level and by its relationship to the mechanical properties of the material, as well as by the microstructure and the existence of internal stresses in the weld and in its heat affected zone [13-16].

The aim of the present paper is to present fatigue crack growth results related to S355 steel joints, with and without fillet welds, subjected to combined bending and torsion loading.

\section{THE MATERIAL AND TEST PROCEDURE}

he tested material is the structural S355 steel, suitable to be used - thanks to its high mechanical strength - in applications involving welded elements, such as buildings, bridges, high-pressure pipelines with large diameters, cranes, overhead cranes, elements of cranes and ships etc.. Table 1 shows the chemical composition of the material and Table 2 some mechanical properties related to monotonic tension tests.

\begin{tabular}{ccccccccc}
\hline $\mathrm{C}$ & $\mathrm{Mn}$ & $\mathrm{Si}$ & $\mathrm{P}$ & $\mathrm{S}$ & $\mathrm{Cr}$ & $\mathrm{Ni}$ & $\mathrm{Cu}$ & $\mathrm{Fe}$ \\
0.2 & 1.49 & 0.33 & 0.023 & 0.024 & 0.01 & 0.01 & 0.035 & Balance \\
\hline
\end{tabular}

Table 1: Chemical composition (in wt \%) of the S355 steel.

\begin{tabular}{ccccc}
\hline$\sigma_{\text {y }}(\mathrm{MPa})$ & $\sigma_{\mathrm{u}}(\mathrm{MPa})$ & $\mathrm{E}(\mathrm{GPa})$ & $\boldsymbol{v}(-)$ & $\mathrm{A}_{5}(\%)$ \\
357 & 535 & 210 & 0.30 & 21 \\
\hline
\end{tabular}

Table 2: Mechanical properties of the S355 steel.

Shapes and dimensions of the tested specimens are presented in Fig. 1. The specimens were obtained from an extruded bar with a diameter of $\varnothing 30 \mathrm{~mm}$. In the case of welded specimens, the two parts were joined by concave or convex fillet joints on both sides, as shown in Fig. 1b, c, while the solid (i.e. the non-welded specimen) is shown in Fig. 1 a.

Hand-made welded joints were made by employing the TIG method in an inert shielding gas (argon) by using a welding wire marked W-42-2-W2Sil according to EN ISO 636. Visual pre-selection of specimens were carried out before the experimental tests. All the tested specimens were subjected to non-destructive tests by using magnetic particle test method under UV light [13] in order to eliminate specimens with unaccetable defects (mainly cracks).

The Vickers hardness measurements were then carried out using a LECO MHT 200 microhardness tester under a load of $100 \mathrm{~g}$, according to the EN ISO 9015-1 requirements.

Metallographic tests were performed with the use of an optical microscope (OLYMPUS IX70) by employing polarized light and phase contrast. The microstructures of the material forming the welded joint and the microhardness test measurement locations are shown in Fig. 2 (magnification 100x).

The test results related to fatigue crack growth under proportional bending and torsion, were obtained in the laboratory of the Department of Mechanics and Machine Design at Opole University of Technology. The tests were performed on the fatigue test stand MZGS - 100 [18, 19], which allows to perform cyclic bending, torsion and synchronous bending and torsion (Fig. 3a). The tests were conducted under force control (in the considered case, the amplitude of total force moment was controlled) with a loading frequency of $28.4 \mathrm{~Hz}$. The bending $\left(\bar{M}_{B}(t)\right)$ and torsion $\left(\bar{M}_{T}(t)\right)$ moments were generated by applying a force on the arm having length of $0.2 \mathrm{~m}$. The total moment has been made to vary over time according to the relation $\bar{M}(t)=\bar{M}_{T}(t)+\bar{M}_{B}(t)$ (Fig. 3b). 
Fatigue tests were performed in the low cycle fatigue (LCF) and high cycle fatigue regime (HCF).

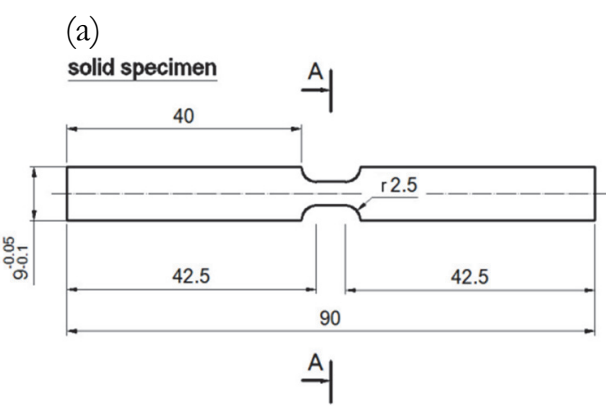

(c) (b)

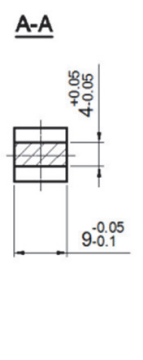

specimen with concave welds

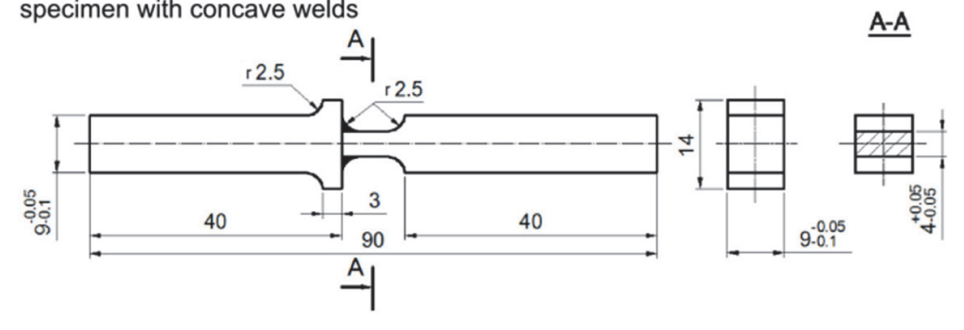

specimen with convex welds

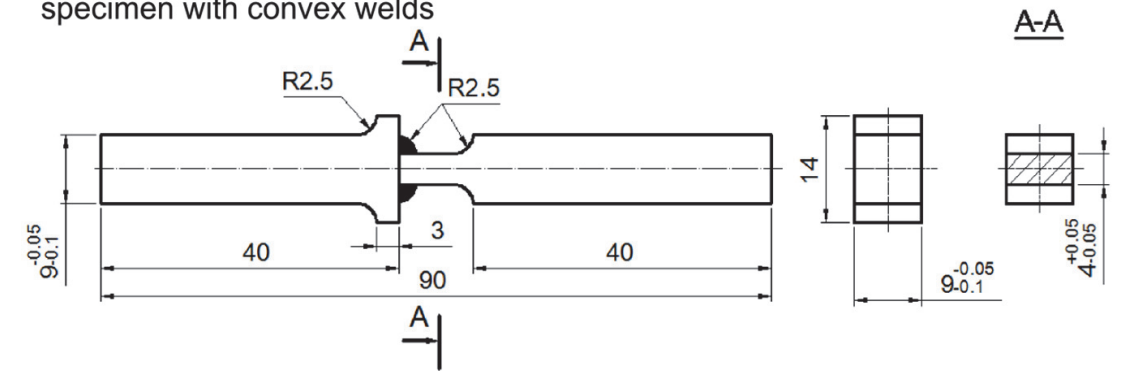

Figure 1: Shape and dimensions of the specimen: (a) solid specimen, (b) specimen with concave welds, (c) specimen with convex welds, (dimensions in $\mathrm{mm}$ ).

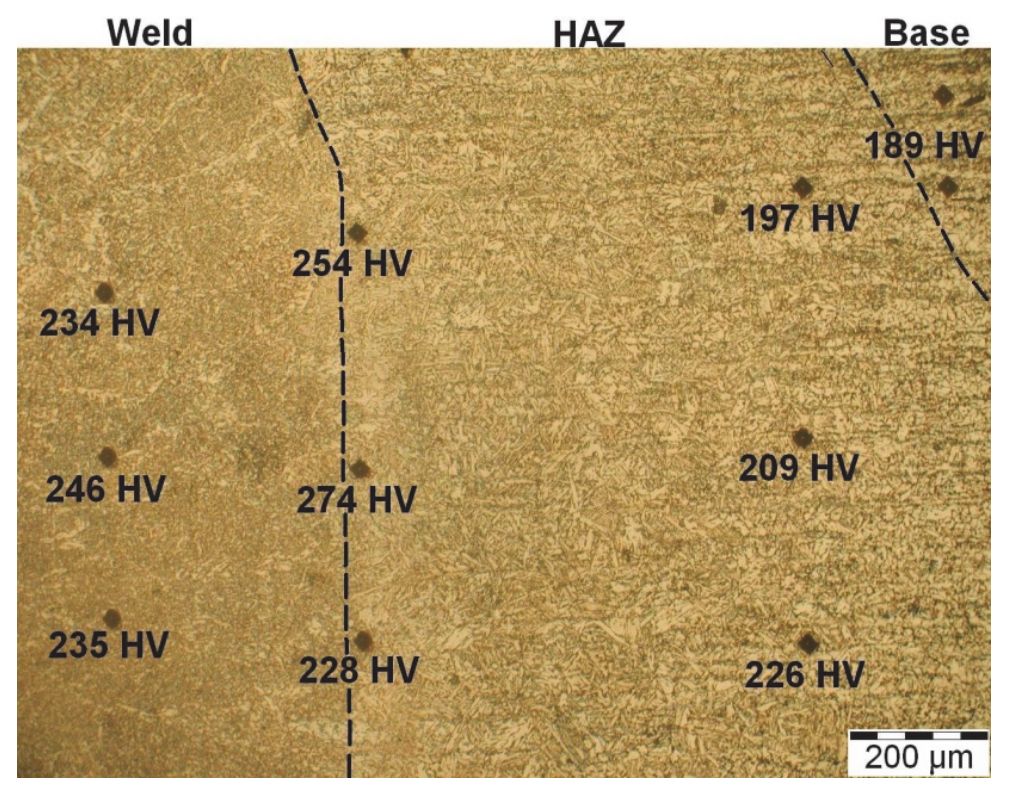

Figure 2: Microstructure of the base material and weld with microhardness measurements.

One-side restrained specimens were tested under fatigue loading characterized by a constant amplitude moment $\mathrm{M}_{\mathrm{a}}=9.2$ $\mathrm{N} \cdot \mathrm{m}\left(\mathrm{M}_{\max }=\mathrm{M}_{\mathrm{a}}+\mathrm{M}_{\mathrm{m}}=18.4 \mathrm{~N} \cdot \mathrm{m}, \mathrm{M}_{\mathrm{m}}\right.$ being the mean value of the applied moment $)$ and load ratios $\mathrm{R}=\mathrm{M}_{\min } / \mathrm{M}_{\max }=$ - 1 and 0 . The theoretical stress concentration factor under bending, estimated as reported in [17], was determined to be $\mathrm{K}_{\mathrm{t}}=1.38$ in the solid specimen with concave weld, while it was 1.56 for the convex weld configuration. The ratio of torsion to bending moment was $\mathrm{M}_{\mathrm{T}}(\mathrm{t}) / \mathrm{M}_{\mathrm{B}}(\mathrm{t})=1$.

The fatigue crack increments were measured through a micrometer located in the portable microscope with a magnification of 20 times and accuracy up to $0.01 \mathrm{~mm}$. At the same time, the number $\mathrm{N}$ of loading cycles was recorded. 
(a)

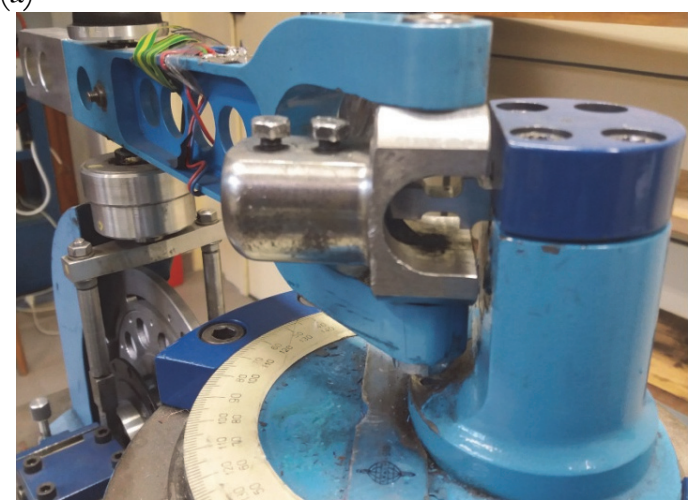

(b)

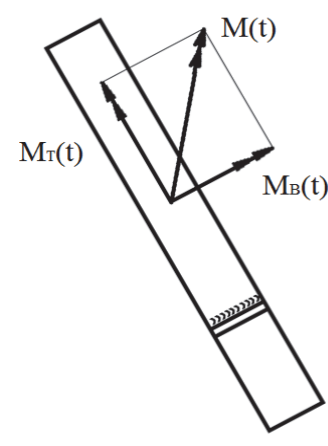

Figure 3: (a) Specimen clamped in MZGS-100 machine, (b) scheme of bending loading applied to the specimen.

\section{TEST RESULTS AND DISCUSSION}

he metallographic tests demonstrated that the microstructure of steel S355 includes ferrite and pearlite grains with band pattern characteristic of drawn rod (base - Fig. 2). Steel structure (solid specimen) was characterized by ferrite grains of the diameter ranging from 5 to $40 \mu \mathrm{m}$ and similar pearlite grains of the diameter ranging from 5 to $45 \mu \mathrm{m}$. Fig. 2 shows three regions, namely the base material, the heat-affected zone (HAZ) and the weld region. The dendritic structure were observed in both kinds of welds. The HAZ shows coarse acicular structure of martensite and bainite of Widmanstatten pattern.

(a)

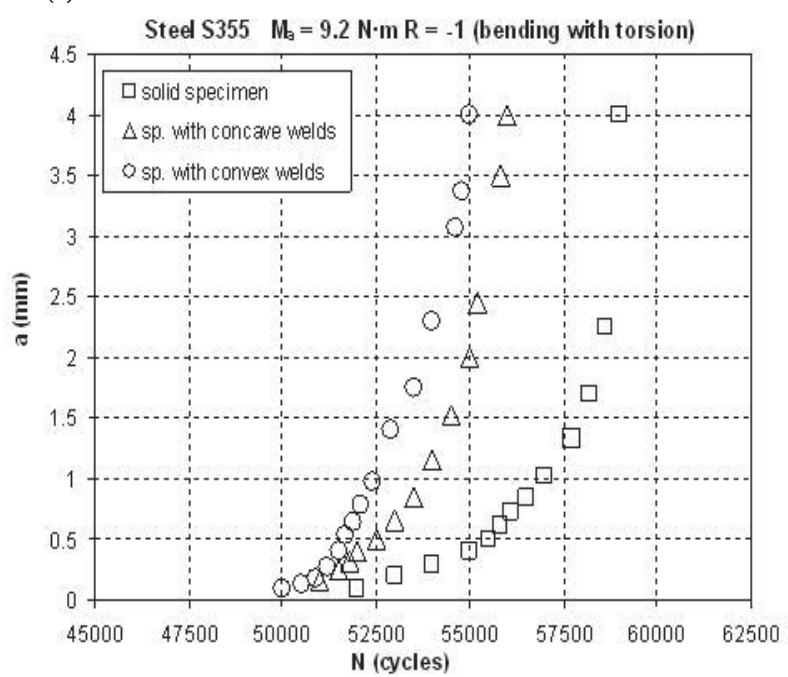

(b)

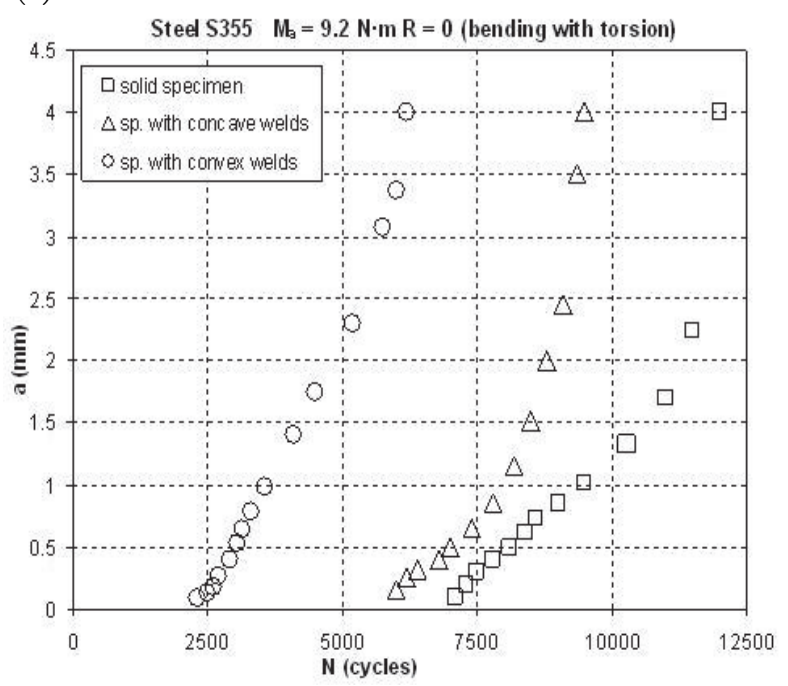

Figure 4: Crack length vs. number of cycles under bending and torsion for: (a) $R=-1$, (b) $R=0$.

Some results concerning the hardness measurements are presented in Fig. 2 where it appears than the microhardness of the welded joints is non-uniform distributed; in particular, it can be appreciated that the microhardness of the welds is higher than of the base material. The highest values of microhardness were measured for concave welds. It can be seen from Fig. 2 that for the base material the microhardness was equal to $189 \mathrm{HV}_{0.1}$, whereas in the heat-affected zone high fluctuations of microhardness in the range 197-274 $\mathrm{HV}_{0.1}$ was observed. In the case of the convex welds, the microhardness was in the range 194-248 $\mathrm{HV}_{0.1}$. The microstructure of the base material was different with respect to that of the welds and HAZ ones. The highest values of a microhardness in the HAZ occur close to the fusion boundary in the concave welds, although these values are comparable to values in the convex welds (max relative error 16\%) [13]. Fig. 4 presents the fatigue crack length versus the number of cycles obtained for the two different adopted stress ratios and for proportional bending and torsion. In Fig. 4 it can be observed that the highest fatigue life indicates specimens made of 
solid material. For the load ratio $\mathrm{R}=-1$ (Fig. 4a), higher life fraction was observed within the so-called initiation period, while for $\mathrm{R}=0$ (Fig. $4 \mathrm{~b}$ ) the propagation life was comparable or higher than the initiation one. There are clear differences between fatigue life in specimens made of solid material and in the welded ones; it can be argued that the fatigue life difference can be determined by the different values of the microhardness of the specimens and by the different material structure.

(a)

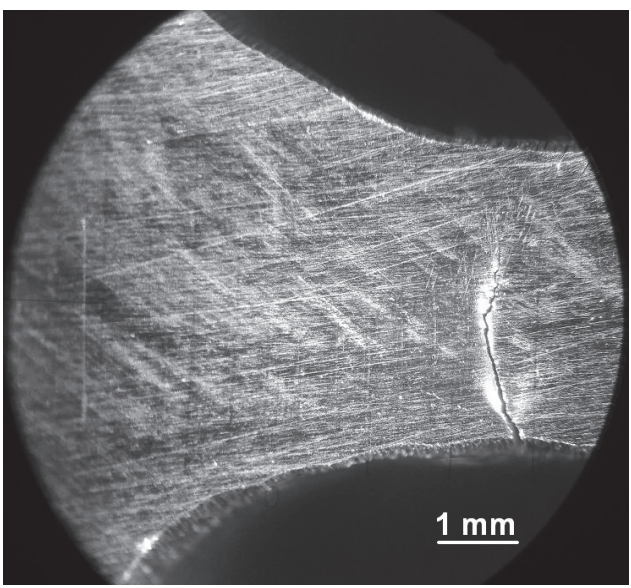

(c)

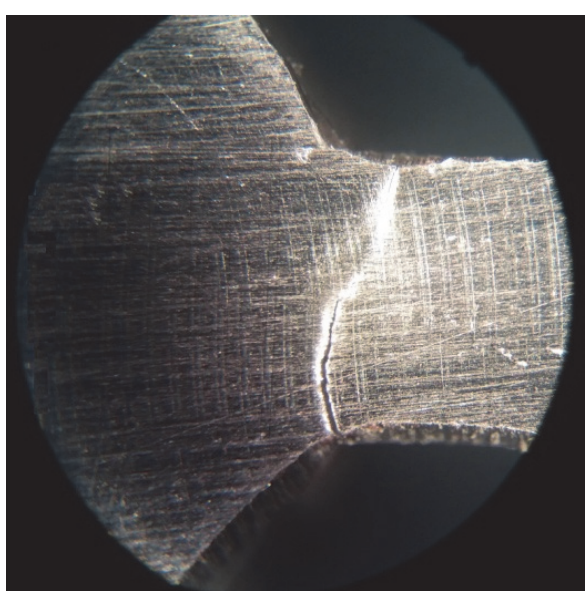

(c)

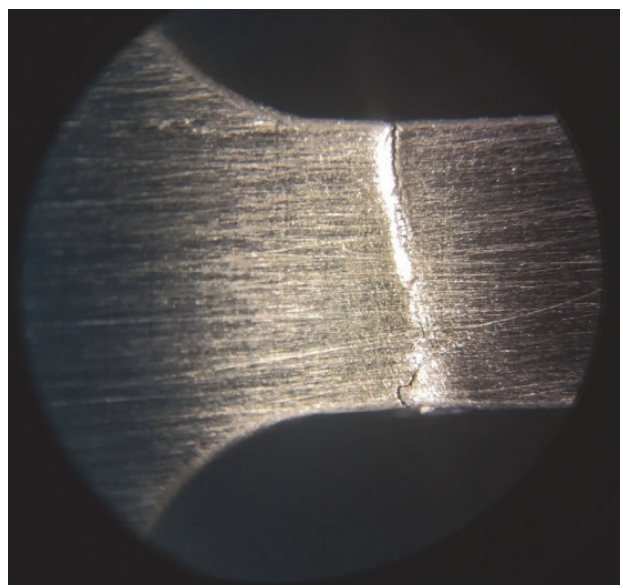

(b)

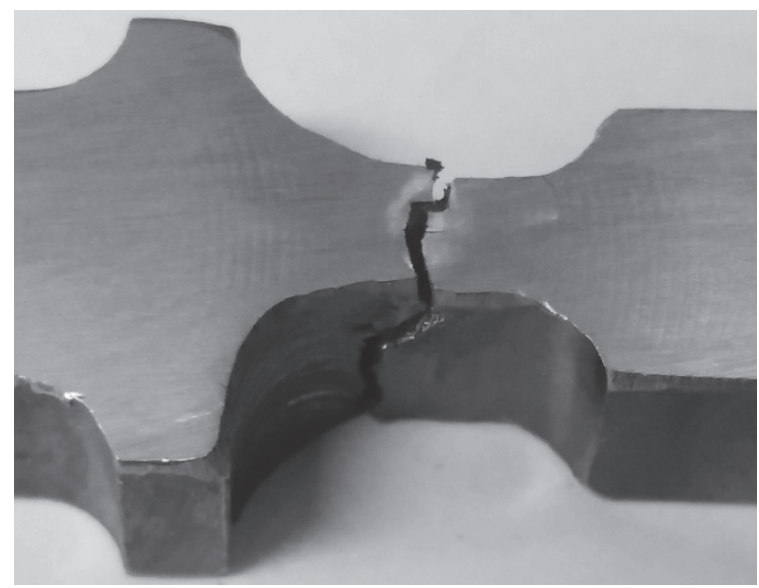

(d)

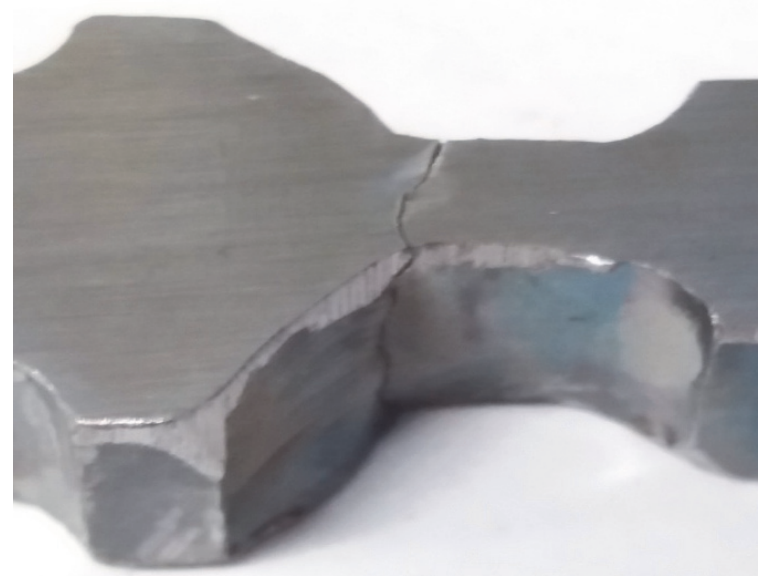

(d)

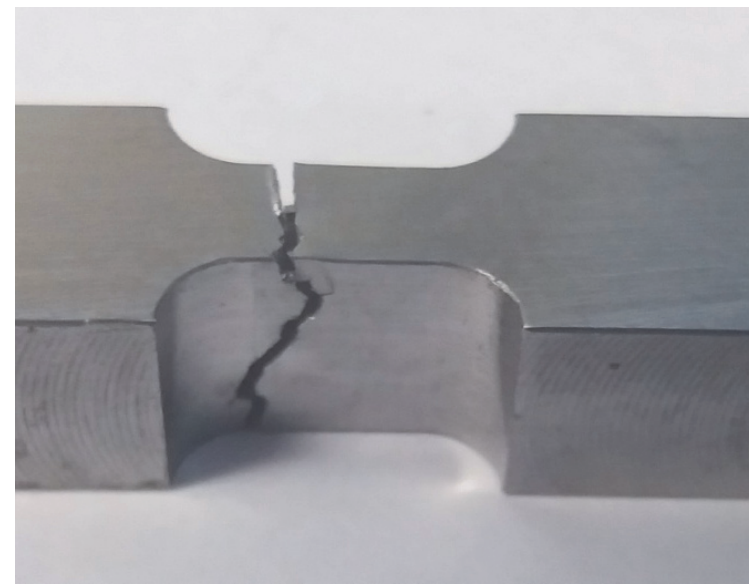

Figure 5: Fatigue crack paths in the specimen under bending and torsion for $\mathrm{R}=-1$ : concave welds (a) side view, (b) final rupture; convex welds (c) side view, (d) final rupture; solid (e) side view, (f) final rupture. 
(a)

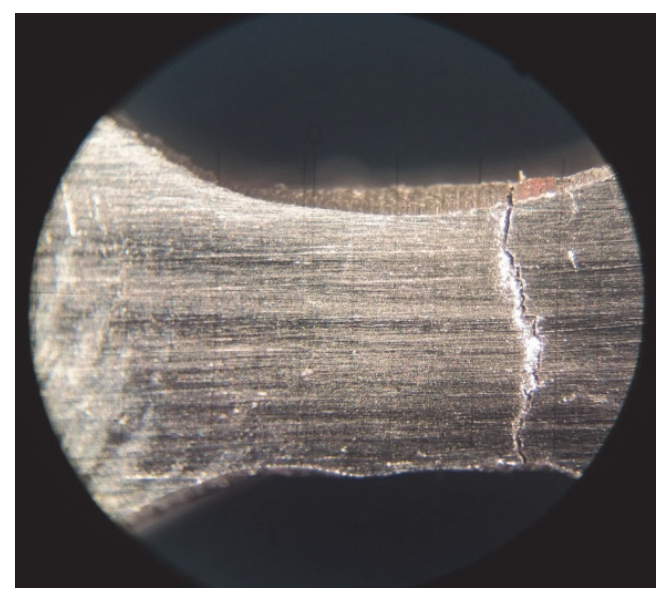

(c)

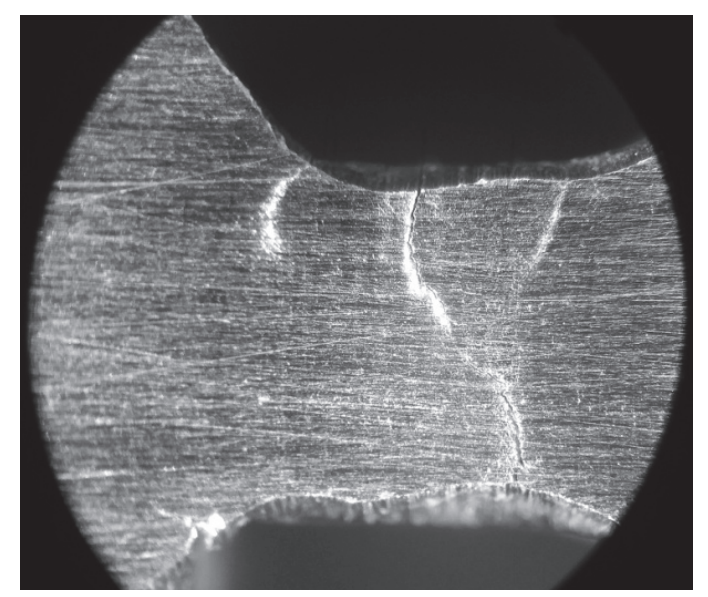

(e)

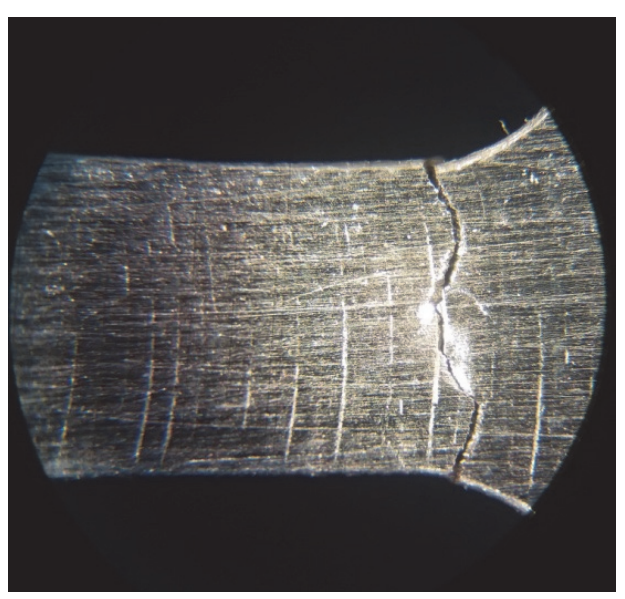

(b)

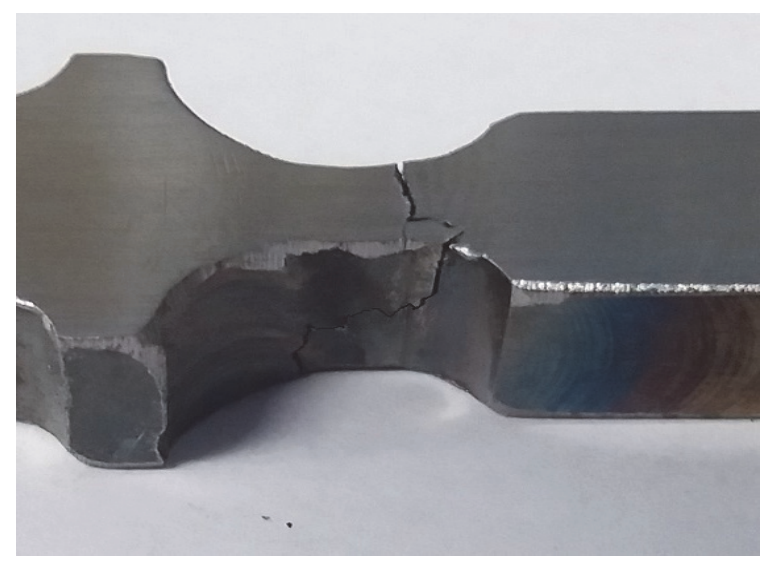

(d)

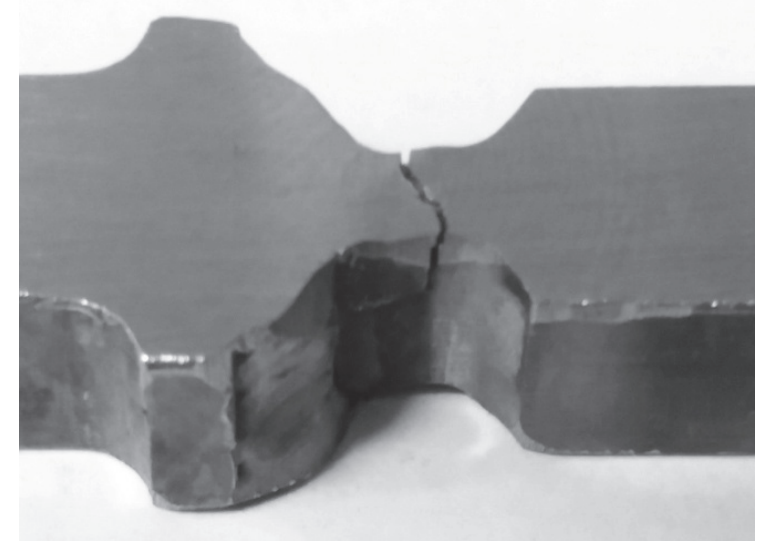

$(\mathrm{f})$

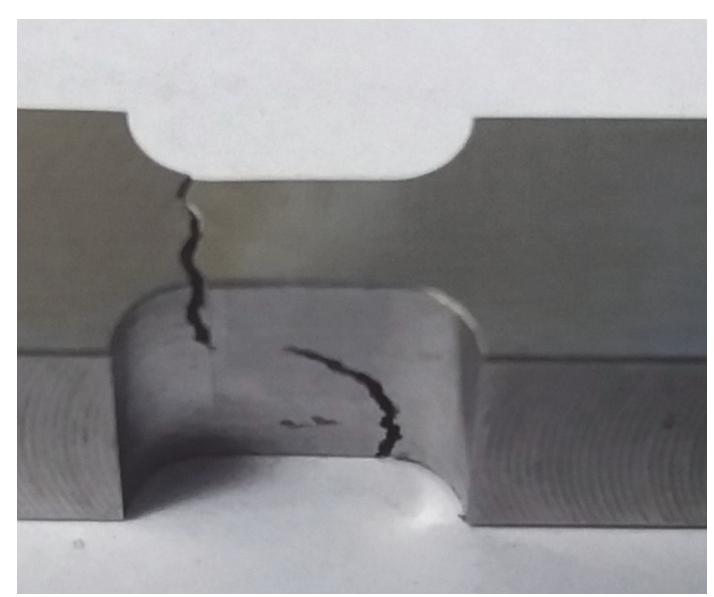

Figure 6: Fatigue crack paths in the specimen under bending and torsion for $\mathrm{R}=0$ : concave welds (a) side view, (b) final rupture; convex welds (c) side view, (d) final rupture; solid (e) side view, (f) final rupture.

Exemplary fatigue crack paths in the tested specimens for load ration $\mathrm{R}=-1$ are shown in Fig. 5, while for load ratio $\mathrm{R}=0$ are displayed in Fig. 6. During the laboratory tests, initiation and subsequent development of cracks from one side of the specimen (from top or bottom) were observed for $\mathrm{R}=-1$; after a certain period of propagation, the crack growth appeared also on the other side. Figs 5(a), (c), (e) present the crack path (magnification of 20 times), while Figs 5(b), (d), 
(f) show the final failed specimens. The rupture occurred after 57800 (concave weld), 56000 (convex weld) and 59000 cycles (solid specimen), respectively. Fig. 6 shows the crack path for damaged specimens after 9000 (concave weld, Fig. 6a, b), 6200 (convex weld, Fig. 6c, d) and 12000 cycles (solid specimen, Fig. 6e, f), respectively. The observed crack path patterns (Fig. 6) are quite different from those of the previous cases; for a specimen with convex welds (tested at $\mathrm{R}=0$ ), three cracks were initiated at the top of the specimen (Fig. 6c), and later one of them became dominant. The pictures reported in Figs 5, 6 show that the obtained crack paths are analogous to those typically occurring in mixed mode of fracture. In all the considered cases the cracks were initiated perpendicular to the maximum normal stress direction. After initiation, crack growths along different planes depending on the local stress state ahead of a crack tip which is strongly correlated to the residual stresses taking place in the material after the welding process.

\section{CONCLUSIONS}

7 he study presented the results concerning the fatigue crack growth in S355 steel specimens subjected to proportional bending and torsion loading. The experimental outcomes allow to state the following conclusions:

1. For all cases, fatigue life of the solid specimens were higher compared to that of the welded specimens.

2. Fatigue crack growth paths in all test specimens started on one-side of the specimen, located at the place of highest stress concentration.

3. The various tested specimens, with and without welds, show different cracking courses.

4. The highest microhardness was measured on the fusion boundary weld.

5. The propagation of cracks usually occurred in the HAZ where the highest microhardness was measured.

\section{REFERENCES}

[1] Lesiuk, G., Szata, M., Rozumek, D., Marciniak, Z., Correia, J.A.F.O., De Jesus, A.M.P. (2017). Energy description of fatigue crack growth process - theoretical and experimental approach. Procedia Structural Integrity, 5, pp. 904-911. DOI: $10.1016 /$ j.prostr.2017.07.128.

[2] Rozumek, D., Marciniak, Z., Lesiuk, G., Correia, J.A.F.O., De Jesus, A.M.P. (2018). Experimental and numerical investigation of mixed mode I + II and I + III fatigue crack growth in S355J0 steel. Int. J. of Fatigue, 113, pp. 160170. DOI: 10.1016/j.ijfatigue.2018.04.005.

[3] Rozumek, D., Marciniak, Z., Lesiuk, G., Correia, J.A.F.O. (2017). Mixed mode I/II/III fatigue crack growth in S355 steel. Procedia Structural Integrity, 5, pp. 896-903. DOI:10.1016/j.prostr.2017.07.125).

[4] Rozumek, D., Marciniak, Z. (2011). Fatigue crack growth in AlCu4Mg1 under nonproportional bending-with-torsion loading. Materials Science, 46(5), pp. 685-694.

[5] Rozumek, D., Faszynka, S. (2017). Fatigue crack growth in 2017A-T4 alloy subjected to proportional bending with torsion. Frattura ed Integrita Strutturale, 42, pp. 23-29. DOI:10.3221/IGF-ESIS.42.03.

[6] Xionglin, D., Fenggui, L., Haichao, C., Xinhua, T., Zhuguo, L., (2016). Microstructure correlation and fatigue crack growth behavior in dissimilar 9 Cr/CrMoV welded joint. Materials Science \& Engineering A, 651, pp. 1018-1030. DOI: 10.1016/j.msea.2015.11.081.

[7] Hobbacher, A., IIW., Recommendations for Fatigue Design of Welded Joints and Components, WRC Bulletin 520, Welding Research Council, New York, 144.

[8] Kawiak, M., Balitskii, A. (2018). Embrittlement of welded joints of tram rails in city environments. Engineering Failure Analysis, 85, pp. 97-103. DOI: 10.1016/j.engfailanal.2017.12.011.

[9] Bielawski, R., Kowalik, M., Suprynowicz, K., Rzadkowski, W., Pyrzanowski, P. (2016). Investigation of riveted joints of fiberglass composite materials. Mechanics of Composite Materials, 52, pp. 199-210. DOI: 10.1007/s11029-016-9573-4.

[10] Carpinteri, A., Brighenti, R., Huth, H.J., Vantadori, S., (2005). Fatigue growth of a surface crack in a welded T-joint. Int. J. Fatigue, 27 (2005) 59-69. DOI: 10.1016/j.ijfatigue.2004.05.007.

[11] Wahab, M.A., Alam M.S. (2004). The significance of weld imperfections and surface peening on fatigue crack propagation life of butt-welded joints. J. Mater. Process. Technol., 153-154, pp. 931-937.

DOI: $10.1016 /$ j.jmatprotec.2004.04.150.

[12] Zhi-Gang, X., Tao, C., Xiao-Ling, Z. (2012). Fatigue strength evaluation of transverse fillet welded joints subjected to bending loads. Int. J. Fatigue, 38, pp. 57-64. DOI: 10.1016/j.ijfatigue.2011.11.013. 
[13] Lewandowski, J., Rozumek, D. (2016). Cracks growth in S355 steel under cyclic bending with fillet welded joint. Theoretical and Applied Fracture Mechanics, 86, pp. 342-350. DOI: 10.1016/j.tafmec.2016.09.003.

[14] Sniezek, L., Szachogluchowicz, I., Gocman, K. (2013). The mechanical properties of composites AA.2519-Ti6A14V obtained by detonation method. Intelligent Technologies in Logistics and Mechatronics Systems, pp. 214-219.

[15] Rozumek, D., Marciniak, Z. (2017). Crack growth of explosive welding zirconium-steel bimetal subjected to cyclic bending. Frattura ed Integrita Strutturale, 42, pp. 40-45. DOI:10.3221/IGF-ESIS.42.05.

[16] Fischer, C., Fricke, W, Rizzo, C.M. (2016). Fatigue tests of notched specimens made from butt joints at steel. Fatigue \& Fracture of Engineering Materials \& Structures, 39, pp. 1526-1541. DOI: 10.1111/ffe.12473.

[17] Thum, A., Petersen, C., Swenson, O., Verformung (1960). Spannung und Kerbwirkung. VDI, Düesseldorf.

[18] Rozumek, D., Marciniak, Z. (2008). Control system of the fatigue stand for material tests under combined bending with torsion loading and experimental results. Mechanical Systems and Signal Processing, 22, pp. 1289-1296. DOI: 10.1016/j.ymssp.2007.09.009.

[19] Kasprzyczak, L., Macha, E., Marciniak, Z. (2013). Energy parameter control system of strength machine for material test under cyclic bending and torsion. Solid State Phenomena, 198, pp. 489-494.

DOI: 10.4028/www.scientific.net/SSP.198.489.

\section{NOMENCLATURE}

$\begin{array}{ll}\mathrm{a} & \text { crack length } \\ \mathrm{A}_{5} & \text { elongation } \\ \mathrm{E} & \text { Young's modulus } \\ \mathrm{K}_{\mathrm{t}} & \text { stress concentration factor } \\ \mathrm{M}_{\mathrm{a}} & \text { amplitude of total moments } \\ \mathrm{M}_{\mathrm{B}} & \text { bending moment } \\ \mathrm{M}_{\mathrm{T}} & \text { torsion moment } \\ \mathrm{M}_{\mathrm{m}} & \text { mean moment } \\ \mathrm{M}_{\max } & \text { maximal value of moment } \\ \mathrm{M}_{\min } & \text { minimal value of moment } \\ \mathrm{N} & \text { number of cycles crack growth } \\ \mathrm{R} & \text { load ratio } \\ v & \text { Poisson's ratio } \\ \sigma_{\mathrm{u}} & \text { ultimate tensile stress } \\ \sigma_{\mathrm{y}} & \text { yield stress } \\ \mathrm{HAZ} & \text { heat affected zone }\end{array}$

